\title{
Research Paper: Monetary Value and the Cost Analysis of a Youth Voluntary Program of Road Safety in Iran
}

\author{
Hamed Seddighi' ${ }^{1}$, Ibrahim Salmani²* ${ }^{*}$, Saeideh Seddighi $^{3}$ \\ 1. Student Research Committee, University of Social Welfare and Rehabilitation Sciences, Tehran, Iran. \\ 2. Department of Health in Emergency and Disaster, Shahid Sadoughi University of Medical Sciences, Yazd, Iran. \\ 3. Department of Social Sciences, Allameh Tabataba'i University, Tehran, Iran.
}

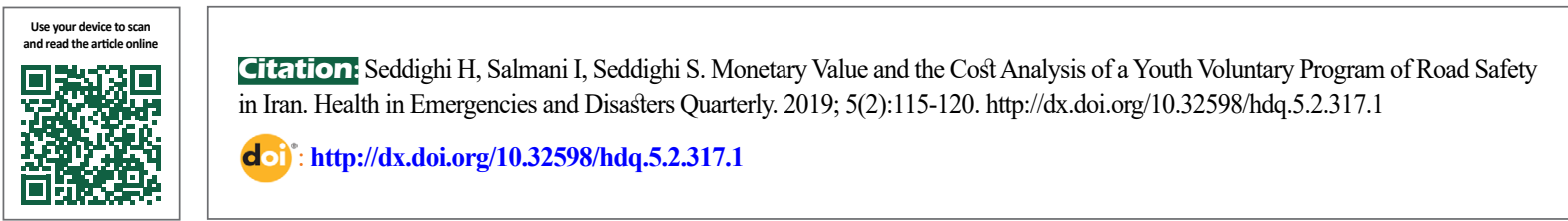

\section{(i) \$)}

Article info:

Received: 28 Apr 2019

Accepted: 31 Nov 2019

Available Online: 01 Jan 2020

\section{Keywords:}

Cost analysis, Monetary

valuation, Volunteering, Youth,

Road safety

\section{ABSTRACT}

Background: Volunteering has great economic and social benefits, but it is neglected due to the nature of the work. This study aimed to assess the monetary aspect of the voluntary activities in the National Plan of Safety and Health of Nowruz Passengers and analyze the cost of the implementation of this plan, regarding youth volunteers.

Materials and Methods: In this descriptive-analytical study, 1574 volunteers outlined in the plan were analyzed with the wage replacement and replacement cost approach for the monetary evaluation of voluntary activities. Also, the cost-benefit analysis of the Red Crescent voluntary plan was calculated by the volunteer investment and value audit technique.

Results: In the mentioned road safety plan, the sum of the economic values of volunteering work was multiplied by the number of working hours of youth volunteers per day. Thus, the number of young people was determined, considering the average wage per hour for these people, the monetary value of $\$ 69885.6$ was obtained for the voluntary activities. Also, the volunteer investment and value audit rate was $\$ 10.6$; it means that every dollar spent by Red Crescent would cost more than $\$ 10$ if it were not voluntary.

Conclusion: According to the present findings, it seems that the National Plan of Safety and Health of Nowruz Passengers had been economically profitable for the Red Crescent population and the government because of its high revenue, compared with its cost.

\section{Introduction}

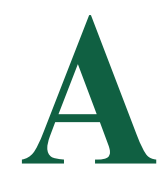

s voluntary works become widespread, it is no longer surprising that governments around the world plan for the economic and social benefits of voluntary activities. In the UK, voluntary activities have contributed about $\$ 64$ billion to the economy of this country. Also, the economic value of these activities has raised over $\$ 16$ billion, in Canada.

According to a comparative study recently conducted in 22 countries, the duration that volunteers spend on voluntary activities includes 5.5 million full-time employees. It is important to note that the profitability of voluntary activities requires planning, investing, orga-

\section{* Corresponding Author:}

Ibrahim Salmani, PhD.

Address: Department of Health in Emergency and Disaster, Shahid Sadoughi University of Medical Sciences, Yazd, Iran.

E-mail:e.salmani.n@gmail.com 
nizing, and training. A recent study in Europe estimated that each dollar of investment in voluntary works will return $\$ 8$. Although the voluntary activities are not a substitute for public services, they are a basic complement to it. Governments are the beneficiaries of promoting voluntary activities, which is one of the fundamental elements in a healthy and democratic society [1].

Kennan et al. [2] reviewed more than 300 different definitions of the term "volunteer" and developed a framework to define the term of volunteer. This framework has provided four dimensions to define a volunteer. The first dimension is free choice, meaning that the volunteer participates freely and without compulsion in a particular activity. The second dimension considers volunteers' reward [3]. According to the definitions of the volunteer, the volunteer does not receive a bonus. Generally, the volunteers can be rewarded, but they should not expect to receive a reward. The most general definition of the volunteer is the receipting reward as the cost. In the third dimension, volunteers are defined according to their work structure.

Two different domains are separated in a more specific definition that only accepts voluntary activities in the formal organizational structure, but the more general definition of some activities includes helping neighbors and friends. The fourth dimension involves the beneficiaries of voluntary services. A more specific definition only accepts volunteering activities aimed at strangers, but other definitions also accept the benefits of friends and relatives. Regarding the four dimensions, this paper defines the volunteers as people who work for a nonprofit organization, the members of the organization, and other people with their willingness and without receiving any wage; they benefit from their voluntary activities [4].

The National Plan of Safety and Health of Nowruz (new year holiday) Passengers is being performed every year in the Iranian holidays of the new year (March 21 to April 5). Regarding that more than 15 million Iranians travel on this holiday [5], the plan becomes important. The purpose of this plan is to increase the awareness and change the attitude of the passengers to reduce the high-risk behaviors (the instruction of the National Plan of Safety and Health of Nowruz Passengers). This plan is held with the participation of Red Crescent volunteers across Iran $[6,7]$. Also, as children are one of the most vulnerable groups in emergencies $[8,9]$, child protection is one of the main aims of the mentioned plan for new year holidays' passengers.

Researching in the field of services without the cost, researchers began to exit the market services, first in the $20^{\text {th }}$ and the early $30^{\text {th }}[10]$. Over the next decades, the monetary value of public goods and the valuing of the volunteer workforce will be a specific target for various researchers in the field of economics and policymaking. Several initiatives have been undertaken in the last decade to identify the importance and scope of volunteering activities, such as the Johns Hopkins Economic Data Project, the Volunteer Assessment Project, and the United Nations Nonprofit Organizations Action Book monitored by the Study Center of Civil Society at Johns Hopkins University [11].

Many beneficiaries are interested in the economic value of volunteer work. For example, social investors are interested in returning their capital. The lobbyists and nonprofit activists use economic valuation to highlight the importance of the volunteering work and volunteering sections to society and policymakers, respectively [12]. They are seeking government subsidies for the voluntary sector. Also, the legislators want to know how helpful the allocated subsidies have been utilized. Economists are interested in the fact that the volunteer sector is much more important in comparison with other sectors. All beneficiaries are interested in statistical information and the monetary values, compared with the qualitative data, on the volunteering activities [13].

\section{Materials and Methods}

In this descriptive-analytical study, considering the expenditures and costs of the National Plan of Safety and Health of Nowruz Passengers, the recovered data, and the number of engaged volunteers, the monetary value was measured for the voluntary activity of Yazd Red Crescent Youth. Achieve this, the alternative methods of cost, replacement method, and wage replacement method were used. Also, the cost-benefit and cost-effectiveness analysis were conducted using the volunteer investment and value audit (VIVA) method. The data were collected from the interviews and daily reports of Red Crescent youth experts in the Yazd Province. The information forms were directly sent to the responsible person of each post, then, the completed forms were sent back to the Province.

The replacement cost and the replacement wage approaches were used to monetarily evaluate the plan. The cost replacement is an input-centric method and focuses on the performed activity and occupation. This method measures the value of the volunteers by substituting the cost of one hour of paid work with one hour of voluntary work in a similar task. 
The replacement wage approach is also known as the shadow pricing model, and directly assesses the performed activity of volunteering work [14]. This model calculates the economic value of volunteers by calculating the hourly wage cost of the workforce for doing the same work [1]. The identification of wage and labor market costs are possible, but searching the cost and amount is challenging and time-consuming. Therefore, in the studies of this method, the average labor cost of the market is considered as the best outcome for the voluntary work [15]. The replacement wage approach has been widely used in previous studies for the industry average wage or the average national wage $[13,16]$.

\section{Cost-Benefit analysis}

The VIVA method analyzes the costs and activities associated with the volunteer program and compares it with the work of the job market. Thus, the resulted ratio represents the amount of return on investments made in the volunteer programs [17]. The allocation of the market value (shadow wage) represents the amount that the organization would have to pay to the workforce if it did not have voluntary workforce services. The VIVA model also performs the cost-benefit and cost-effectiveness analyses through the ratio of the input (resources used to support the volunteer) and the output (the monetary value of the time spent by the volunteer), and shows the organization's revenues for each dollar spent [18]. The VIVA rate (investment on volunteer and the economic value of volunteering work) is calculated with the following formula [17]:

In this formula, the investment amount of volunteers includes the costs done for volunteers.

\section{$V I V A=\frac{\text { Economic Value of Volunteer }}{\text { Investment Amount of Volunteer }}$}

\section{Results}

The National Plan of Safety and Health of the Nowruz Passengers of Yazd Province included 27 fixed posts forecasted at the entry and exit ports of the cities for 16 days. At each of these stations, two persons provided voluntary services 12 hours per day. Also, 20 stations were launched for the child-friendly spaces that included 20 trainers cooperated voluntarily for 18 days. The plan included 1574 volunteers that were paid only for the cost of food and transportation for the cooperation in the Nowruz.

According to Table 1, the Yazd Red Crescent population has spent $\$ 6547.7$ on young people volunteering in the National Plan of Safety and Health of the Nowruz Passengers. This cost includes food, travel, equipment, supplies, and the training costs of each person.

Tables 2 and 3 represent the economic value of the volunteer work. These investigations indicate the cost that Red Crescent would have paid if it intended to employ personnel instead of the recruitment of young people to the plan. Based on the minimum wage of employees in 1994, the minimum wage per hour has been $\$ 1.43$ in Iran.

Tables 2, also shows the kind of staff that should be employed if no young volunteers were used. To determine the economic value, three main activities were selected: informing the passengers, assessing the health of passengers (including the blood pressure and blood glucose measurements), and working in a child-friendly environment.

Table 1. Yazd Red Crescent population spent costs for the youth of the National Plan of Safety And Health of the Nowruz passengers

\begin{tabular}{|c|c|c|c|}
\hline Costs & Description & No. & Cost (US \$) \\
\hline Food & $\begin{array}{c}\text { The minimum cost paid for a hot meal at a } 12 \text {-hour post is } \$ 4.61 \text { for each } \\
\text { person }\end{array}$ & 896 & 4135.4 \\
\hline Transportation & $\begin{array}{l}\text { The minimum cost paid for traveling to the post office or the Red Cres- } \\
\text { cent Branch is } \$ 1.53 \text { for each person }\end{array}$ & 896 & 1378.5 \\
\hline $\begin{array}{l}\text { Equipment and } \\
\text { supplies }\end{array}$ & $\begin{array}{l}\text { The minimum cost of the necessary equipment, such as identity cart } \\
\text { cover, etc., for the presence of a volunteer, is } \$ 31.9 \text { for each post }\end{array}$ & 27 (stations) & 861.5 \\
\hline \multirow[t]{2}{*}{ Training } & The cost of training volunteers at each post & & 172.3 \\
\hline & Sum & & 6547.7 \\
\hline
\end{tabular}


The second column of Tables 2 represents the needed specialties that would be used instead of the young volunteers. The number of volunteers is the number of young people who volunteered to work in the designated posts for the 16 days of the plan in the Yazd Province. Overall, 1574 day working young volunteers have acted in three different branches.

Tables 2 indicates the sum of the economic value of volunteering work in the plan. This value is obtained using the wage replacement approach (including the minimum wage) by multiplying the working hours of youth volunteers per day, the number of volunteers, and the minimum wage per hour. The results of the wage replacement approach (minimal) showed the monetary value of \$28 889.04 for the voluntary activity of the Yazd Red Crescent youths during the Nowruz.

Table 3 shows the calculation of the sum of the economic value of volunteering work in the plan using the wage replacement approach. Considering the average wage received by the Red Crescent staff, the economic value has resulted from the multiplication of the working hours of youth volunteers per day, the number of young people, and the average wage earned per hour. The results of the wage replacement approach showed a monetary value of $\$ 69885.6$.

Considering two types of obtained monetary values, the VIVA rate is calculated as follows:

Sum of the Volunteering Hours of Plan=Number of Volunteers $\times$ Rate of Volunteering Hours per day $=1574 \times 12=18888$

Number of Employees (in the case of volunteer nonuse)

\section{Sum of the Volunteering Hours of Plan}

Number of Plan Days $\times$

Working Hours of Employees

Number Employees (in the case of volunteer nonuse)= $\frac{18888}{16 \times 7.5}=157.4 \cong 157$

Hypothetically, if young volunteers were not used in the plan, several full-time staff would be employed. The following calculations determine that 157 full-time employees are needed to hold the safety and health plan in the Yazd Province. We supposed 16 working days (the duration of the plan), and 7.5 working hours per day (regarding the working hours of the Yazd Province for employees). Therefore, the number of required employees is obtained, dividing the number of the hours of the plan by the approved hours and the number of the days of the plan.

\section{Discussion}

The present findings showed that the economic value of volunteering activities is significant, besides, the use of different methods could greatly change the results. In the wage replacement approach, using the average wage increases the economic value nearly three times, compared with the use of minimum wage. Similarly, another researcher pointed to the problems that exist in the determination of a figure for all volunteers: the exaggeration or underestimation of volunteering activity [2]. One of the problems in the wage replacement approach was the finding of equivalent activities for professionals in their related businesses. The wages of the professionals with a high experience, knowledge, and skills were considered equal to the wages of non-trained or non-skilled volunteers, thus, their financial values were assumed equally.

Table 2. Evaluation of the voluntary activities of Yazd Red Crescent youths in the National Plan of Safety and Health of Nowruz passengers, in 2016, using the wage replacement approach

\begin{tabular}{|c|c|c|c|c|c|}
\hline Activity & $\begin{array}{l}\text { Position (in the case of } \\
\text { Employment) }\end{array}$ & $\begin{array}{l}\text { Minimum } \\
\text { Wage per } \\
\text { Hour (US \$) }\end{array}$ & $\begin{array}{c}\text { Numbers } \\
\text { of Volun- } \\
\text { teers }\end{array}$ & $\begin{array}{c}\text { Rate of } \\
\text { Working } \\
\text { (h/d) }\end{array}$ & $\begin{array}{l}\text { Monetary Value } \\
\text { (US \$) }\end{array}$ \\
\hline Informing and guiding passengers & Clerk & 1.43 & 1024 & 12 & 17743.44 \\
\hline $\begin{array}{l}\text { Measuring the health of pas- } \\
\text { sengers (blood glucose and blood } \\
\text { pressure) }\end{array}$ & Nurse & 2.3 & 180 & 12 & 4968 \\
\hline Work at child-friendly space & Kindergarten trainer & 1.43 & 360 & 12 & 6177.6 \\
\hline \multicolumn{5}{|c|}{ Sum } & 28889.04 \\
\hline
\end{tabular}


Table 3. Evaluation of the volunteer activities of Yazd Red Crescent Youths in the National Plan of Safety and Health of Nowruz Passengers by wage replacement Approach

\begin{tabular}{|cccccc}
\hline Activity & $\begin{array}{c}\text { Position (in the Case } \\
\text { of Employment) }\end{array}$ & $\begin{array}{c}\text { Minimum Wage Per } \\
\text { Hour (US \$) }\end{array}$ & $\begin{array}{c}\text { Number of } \\
\text { Volunteers }\end{array}$ & $\begin{array}{c}\text { Rate of Working } \\
\text { (h/d) }\end{array}$ & $\begin{array}{c}\text { Monetary } \\
\text { Value (US \$) }\end{array}$ \\
\hline $\begin{array}{c}\text { Informing and guiding } \\
\text { passengers }\end{array}$ & Clerk & 3.7 & 1034 & 12 & 45909.6 \\
$\begin{array}{c}\text { Measuring the health } \\
\text { of passengers (blood } \\
\text { glucose and blood } \\
\text { pressure) }\end{array}$ & Nurse & 3.7 & 180 & 12 & 1992 \\
\hline $\begin{array}{c}\text { Work at child-friendly } \\
\text { space }\end{array}$ & Kindergarten trainer & 3.7 & 360 & 12 & 15984 \\
\hline
\end{tabular}

The monetary valuation of the Yazd Red Crescent Youth volunteers in the National Plan of Health and Safety of Nowruz Passengers was conducted in two ways: the minimum wage replacement and the average wage replacement. A lower monetary valuation was observed for volunteering youth in the minimum wage replacement approach, compared with the average wage replacement. This approach showed the cost that the Yazd Red Crescent population would have to pay if it intended to hire new people instead of using volunteers, in the plan. On the other hand, the obtained amount from the average wage replacement approach indicated the cost that would be paid if the existing employees of the Red Crescent Society of the Province were to be used in the plan. This figure is caused by the higher average wage of the employees of the Province's population, which was obtained from the minimum multiplier wage of the other approach. Also, results specified that if the volunteer forces are not used, it will require 157 full-time employees to work on the plan, in the Yazd Province.

The VIVA method was used for the cost-benefit analysis (the investment on volunteer and the economic value of volunteer work) of the plan. The results revealed that if the valuation is carried out by the wage replacement approach, the VIVA rate will be 4.4 ; it means that for each dollar cost created by the Red Crescent population in the voluntary plan $\$ 4.4$ will be returned to the Red Crescent, in 2015. If the wage rate is calculated using the average method, the VIVA rate will be around 10.6; it means a high return on this voluntary plan and the high value of this activity. Therefore, the higher the VIVA rate, the more money is returned; this is where the high value of volunteering activity is determined. In addition to the high monetary value of voluntary activities, this figure represents cost control in this plan, and ensures its survival and economic sustainability during the country's economic problems.

Finding the professional jobs associated with conducted activities in the volunteer projects is a difficult matter that can be considered as the main limitation of the study. Also, this limitation has been mentioned by Vallencourt [19] in a similar study subject.

\section{Conclusion}

According to the findings, it seems that the voluntary plan for the safety and health of the new year holidays passengers had been economically profitable for the Red Crescent population and the government, because of its high revenue compared with its cost. Comparing the cost of volunteers and recruited personnel, using volunteers effectively reduces the total cost, besides, the organizations with volunteer workers have lower indirect costs.

\section{Ethical Considerations}

\section{Compliance with ethical guidelines}

All ethical principles are considered in this article. The participants were informed about the purpose of the research and its implementation stages; they were also assured about the confidentiality of their information; moreover, they were free to leave the study whenever they wished, and if desired, the research results would be available to them.

Funding

This research did not receive any grant from funding agencies in the public, commercial, or non-profit sectors. 


\section{Authors' contributions}

Conceptualization, methodology: Hamed Seddighi; Investigation, writing - review \& editing: Hamed Seddighi, Ibrahim Salmani; Original drafts, supervision: All authors.

\section{Conflict of interest}

The authors declared no conflict of interest.

\section{Acknowledgments}

We sincerely thank those who cooperated with us conducting this study, especially, Iranian Red Crescent volunteers.

\section{References}

[1] Bowman W. The economic value of volunteers to nonprofit organizations. Nonprofit Management and Leadership. 2009; 19(4):491-506. [DOI:10.1002/nml.233]

[2] Cnaan RA, Handy F, Wadsworth M. Defining who is a volunteer: Conceptual and empirical considerations. Nonprofit and Voluntary Sector Quarterly. 1996; 25(3):364-83. [DOI:10.1177/0899764096253006]

[3] Seddighi H, Salmani I. Online volunteering, a way to reduce health inequalities: A review study. Journal of Community Health Research. 2018; 7(4):256-64. [DOI:10.18502/jchr.v7i4.273]

[4] Seddighi H. [Monetary value of voluntary work and cost-benefit analysis of a voluntary plan in Yazd Red Crescent Society, Iran (Persian)]. Journal of Rescue and Relief. 2017; 8(1-2):14459. https:/ / www.sid.ir/fa/journal/ViewPaper.aspx?id=292012

[5] Iranian Student's News Agency. Nowruz trip statistics, 2015 [Internet]. 2017 [Updated 2017 Oct. 1]. Available from: http://www.isna.ir/news/94011603883/15

[6] Seddighi H. The Performance of the Iranian Red Crescent by launching testing centers for the Coronavirus Disease. Disaster Medicine and Public Health Preparedness. 2020; 1-2. [DOI:10.1017/dmp.2020.167] [PMID] [PMCID].

[7] Seddighi H, Morovati Sa. Efficiency evaluation of road relief bases of Yazd Province Red Crescent Society in new year plan. 2013; 5(3):18-26.

[8] Seddighi H, Salmani I, Javadi MH, Seddighi S. Child abuse in natural disasters and conflicts: A systematic review. Trauma, Violence, \& Abuse. 2019; 1524838019835973. [DOI:10.1177/1524838019835973] [PMID]

[9] Seddighi H, Salmani I. Gender differences in children mental health disorders after earthquakes in Iran: A systematic review. Journal of Community Health Research. 2019; 8(1):54-64. [DOI:10.18502/jchr.v8i1.562]

[10] Breuer C, Wicker P. Sports development report 2009/2010-analysis of the sports clubs' situation in Germany (abbreviated version). Cologne: Sportverlag Strauß; 2011.
[11] Salamon LM, Sokolowski SW, Haddock MA. Measuring the economic value of volunteer work globally: Concepts, estimates, and a roadmap to the future. Annals of Public and Cooperative Economics. 2011; 82(3):217-52. [DOI:10.1111/j.1467-8292.2011.00437.x]

[12] Brown E. Assessing the value of volunteer activity. Nonprofit and Voluntary Sector Quarterly. 1999; 28(1):3-17. [DOI:10.1177/0899764099281001]

[13] Hustinx L, Cnaan RA, Handy F. Navigating theories of volunteering: A hybrid map for a complex phenomenon. Journal for the Theory of Social Behaviour. 2010; 40(4):41034. [DOI:10.1111/j.1468-5914.2010.00439.x]

[14] Pho YH. The value of volunteer labour and the factors influencing participation: Evidence for the United States from 2002 through 2005. Review of Income and Wealth. 2008; 54(2):220-36. [DOI:10.1111/j.1475-4991.2008.00271.x]

[15] Mook L, Handy F, Ginieniewicz J, Quarter J. The value of volunteering for a nonprofit membership association: The case of ARNOVA. Nonprofit and Voluntary Sector Quarterly. 2007; 36(3):504-20. [DOI:10.1177/0899764007300388]

[16] Colonna CM. The economic contribution of volunteerism toward the value of our cultural inventory. Journal of Cultural Economics. 1995; 19(4):341-50. [DOI:10.1007/ BF01073996]

[17] Handy F, Mook L. Volunteering and volunteers: Benefit-cost analyses. Research on Social Work Practice. 2011 21(4):412-20. [DOI:10.1177/1049731510386625]

[18] Handy F, Srinivasan N. Valuing volunteers: An economic evaluation of the net benefits of hospital volunteers. Nonprofit and Voluntary Sector Quarterly. 2004; 33(1):2854. [DOI:10.1177/0899764003260961]

[19] Vaillancourt F. To volunteer or not: Canada, 1987. Canadian Journal of Economics. 1994; 27(4):813-26. [DOI:10.2307/136185] 